\title{
Things that help out: designing smart wearables as partners in stress management
}

\author{
Xueliang (Sean) $\mathrm{Li}^{1} \cdot$ Marco C. Rozendaal ${ }^{1} \cdot$ Kaspar Jansen ${ }^{1} \cdot$ Catholijn Jonker $^{2} \cdot$ Eric Vermetten $^{3,4}$
}

Received: 20 November 2018 / Accepted: 10 June 2020 / Published online: 20 June 2020

(c) The Author(s) 2020

\begin{abstract}
We propose an approach to designing smart wearables that act as partners to help people cope with stress in daily life. Our approach contributes to the developing field of smart wearables by addressing how technological capabilities can be designed to establish partnerships that consider the person, the situation, and the appropriate type of support. As such, this study also contributes to healthcare by opening up novel technology-supported routes to stress treatment and care. We present the results of a phenomenological study conducted with three war veterans who suffer from chronic posttraumatic stress disorder. We describe how their experiences of dealing with their stress informed our design approach, and discuss the implications of these results on smart wearables and stress management in general. We conclude by reflecting on the limitations of this study and directions for future work.
\end{abstract}

Keywords Interaction design · Stress management · Smart wearables · Chronic PTSD · Wearable technologies · Affective computing

\section{Introduction}

Xueliang (Sean) Li

X.Li-8@ tudelft.nl

Marco C. Rozendaal

M.C.Rozendaal@tudelft.nl

Kaspar Jansen

K.M.B.Jansen@tudelft.nl

Catholijn Jonker

C.M.Jonker@tudelft.nl

Eric Vermetten

E.Vermetten@lumc.nl

1 Faculty of Industrial Design Engineering, Delft University of Technology, Landbergstraat 15, 2628 CE Delft, The Netherlands

2 Faculty of Electrical Engineering, Mathematics and Computer Science, Delft University of Technology, Mekelweg 4, 2628 CD Delft, The Netherlands

3 Leiden University Medical Center, Leiden, The Netherlands

4 ARQ National Psychotrauma Center, Diemen, The Netherlands
'On my wrist, I have a bracelet. It senses my pulse, respiration, and has a GPS system. It knows how to help me deal with my anger, and it has witnessed many difficult moments I've been through. It's my best friend. One day, we were at a 'Guns ' $n$ Roses' concert. Before we set out for the concert, I tenderly rubbed the surface of the bracelet to tell it I was in a good mood, so that it would be lenient with me. While we were waiting outside the entrance, more and more people joined the line. The bracelet sensed my agitation and started to contract gently. Feeling this made me aware of my rising tension. I looked for a distraction by talking to my wife and my friends. After we were seated, it was my turn to get beer. Seeing the crowded line at the bar made me nervous and the bracelet started to contract again with a bit more intensity. As I joined the line, I tapped the bracelet with my fingers to let it know I was OK. When it was my turn to order beer, somebody suddenly jumped in front of me. I started shaking with anger! The bracelet grabbed me firmly by my wrist and I realized I needed to step out of the situation before I lost my temper. I went back to my friends to ask if they could order beer for me...' 
Above is a fictional scenario given by Jason, aged 57, a war-veteran who was diagnosed with post-traumatic stress disorder (PTSD) after his military service. Dealing with stress is a chronic condition that he has to face on a daily basis. In a co-design workshop, Jason proposed this concept of a bracelet to help him deal with stress. As can be seen above, the bracelet senses Jason's stress not only via his biosignals (pulse and respiration) and contextual information (location), but also through direct dialog with him (rubbing and tapping). Based on this, the bracelet provides personalized advice by contracting at different levels of intensity which helps him take action. Jason further described this bracelet as his "best friend" who knew him well and on which he could always rely.

This example illustrates how smart wearables could help people manage their daily stress as partners. In this paper, we propose a design approach that introduces the notion of partnership, adding to current developments in the use of smart wearables for daily stress management. Stress is an important aspect of mental health which, if not dealt with properly, could result in reduced quality of life, inefficient work, and even chronic diseases (Steptoe et al. 1996; Anderson et al. 2012). Wearable technologies are increasingly being used to address this. Despite the variety of sensing methods and interventions, there is still a lack of holistic perspective to help designers understand the dynamics of daily stress, and guide them to design appropriate wearable technologies. We propose an approach that provides a direction to associate the multimodal sensing of stress, types of support (interventions), and the relationship experienced by the user with the wearable.

In the following parts, we present the development of this approach by examining technological capabilities of smart wearables, therapeutic partnerships in stress treatment and practice, and theories of designing computers as partners in human-computer interaction (HCI). Based on this approach, we conducted a phenomenological study with three veterans with PTSD. Our results provide an empirical basis on which we identified design opportunities and challenges to design smart wearables as partners. We discuss how this study helped us to enrich this approach. We conclude this paper by reflecting on limitations of this study and directions for future work.

\section{Developing a design approach}

\subsection{An integrated perspective on stress}

Stress is a dynamic process that involves both a neurophysiological and a psychological perspective (Lovallo 2015). A set of changes in physiological signals (such as heart rate, blood pressure, and respiratory rate) occur when people experience stress which indicates a biological process of the body preparing for active behaviors (exemplified by the "fight-or-flight" response). Stress is also a psychological concept. Lazarus and Folkman's (1984) classic transactional model of stress forms the basis for our understanding. In this model, stress emerges as a result of exceeding the demands of the environment, and depends on the cognitive and behavioral efforts taken by the person to address its sources (problem-focused coping) or to regulate the emotional effects (emotion-focused coping). Amongst all the sources of stress, minor stressors that emerge from daily activities (or "daily hassles") play an important role which, if not dealt with properly, can lead to stress-related mental illness and/or exacerbate existing symptoms (Nicolson 1992; Brantley and Jones 1993).

\subsection{Wearable technologies for daily stress}

Current wearable technologies are capable of sensing stress from multiple sources and providing multimodal stress interventions. Physiological sensors form the mainstream of continuous stress measurement, and provide proximal information about people's current stress state. Moreover, research shows the possibility to indicate stress through analysis of people's (online) activities, such as the use of phone applications (Wang et al. 2014; Ferdous et al. 2015), working schedules (Bakker et al. 2012), multitasks (Mark et al. 2014), and posts on social networks (Schwartz et al. 2014; Reece and Danforth 2017). These methods provide useful information to help indicate potential causes of stress and predict upcoming stressful events. However, these are privacy sensitive and should be applied with care in real life. Other methods of sensing include the smartphone applications through which users can report their stress in forms of tags or text (e.g., Adams et al. 2014). This method records empirical evidence regarding a person's experienced stress, but may require extra efforts from the user and withdrawal from current activities.

A variety of commercial products and research prototypes that intervene in daily stress are available. Examples include those that send just-in-time stress notifications to users based on their bio-signals (e.g., Cruz et al. 2015). The challenge is to decide the threshold at which point to send such signals. Research (MacLean et al. 2013) shows that that synchronous representation of stress might even worsen the situation. Some applications translate biofeedback into visualization to trigger retrospective selfreflection (e.g., Sanches et al. 2010), although this can result in problems that people are overwhelmed or feel ashamed by their data (Kelley et al. 2017). Some (commercial) products such as Apple Watch and Fitbit combine the bio-sensed signals with relaxation exercises. We also found applications that target people with mental illness by 
applying therapeutic methods, such as phone applications that provide support by mental health professionals and those initiating peer support among people who share the same experience (Donker et al. 2013; Smedberg and Sandmark 2012). We also found research projects that explored modalities and tangible interfaces of smart wearables as ways of emotional communication. For example, Uğur et al. (2011) developed a set of form-changing garments as ways of communicating emotions between couples.

However, despite the variety of sensing and intervention methods provided by wearable technologies, there is still a lack of design knowledge about when and how to provide support to help people to deal with their daily stress (Sanches et al. 2010; Sharmin et al. 2015). To answer these questions, we searched for inspiration from human and animal partners that help people manage their stress.

\subsection{Partnerships as therapeutic relationships}

We elaborate on three types of partnerships identified in stress treatment and individual management: client-therapist, interpersonal, and human-pet partnerships. First, therapists serve as professional partners in stress-illness management. The partnership between therapists and patients is built on a sense of authority. Therapists maintain an objective perspective when analyzing patients' stress and its causes. They are trained to be sensitive to problematic issues and to be able to recognize "warning signs" of stress (Miller 1998). They provide people with practical techniques and skills to cope with stress, and help them develop positive ways to perceive what triggers their stress (Friedman 2015).

Second, interpersonal partners are people in the individual's social network who are able to help when needed. When faced with stress, people tend to seek help from others, such as family members, spouses, coworkers and friends. These partners help by providing information and advice (informational support), assistance and service (tangible support), and comforting, shared concern and the sense of care and love (emotional support) (Patterson 2003). This support provides a "buffering effect", protecting the person from negative effects of stress (Cohen and Wills 1985).

A third and interesting partnership is that between humans and animals (pets). Holbrook et al. (2001) claimed that the human-pet companionship resembles that of humans' in providing care and comfort, self-reflection, and in-depth communication (if not verbal). Another study by Dotson and Hyatt (2008) shows that dogs can motivate their owners to be more active and adapt their life patterns accordingly. Service dogs have been introduced as an effective method to help people recover from chronic stress illness (Yount et al. 2013; Vincent et al. 2017).

\subsection{Computers as partners}

Considering computers as partners is not new in the field of HCI. Janlert and Stolterman's (1997) proposed the character of things as a coherent set of the characteristics manifested by the product through its appearance, functions, and movements. Discussions continue in the field of HCI with an emphasis on their increasing intelligence and permeation into people's everyday lives. Compared with the counterparts of humans and animals, attention has been paid to the interdependency and collaboration between humans and computers. For example, Jacucci et al. (2014) proposed the concept of partnership (or symbiotic relationship) where both humans and computers maintain independent goals and agency. Farooq and Grudin (2016) talked about the collaboration between humans and computers in the name of negotiation, to achieve mutual understanding and shared goals. In design, Rozendaal (2016) emphasized how smart everyday things can be designed as collaborative partners that empower people to engage in activities which people are otherwise either unmotivated or unable to do. Cila et al. (2017) suggested using agents as a metaphor to describe the affordances, challenges, and opportunities engendered by current and future smart networked products.

\subsection{Designing smart wearables as partners}

Based on this discussion, we propose a design approach to design smart wearables as partners. We suggest designing the interaction between the wearable and wearer as an ongoing dialogue, through which the wearable can build up an understanding of the person and situation, and provide appropriate support. This approach is composed of three aspects that designers should take into consideration, as shown in Fig. 1. By means of sensing, we suggest designers be aware of the sources of stress-related data and how they can contribute to the understanding of the users' stress situation. With providing support, we refer to the behavioral changes triggered by the interaction with smart wearables,

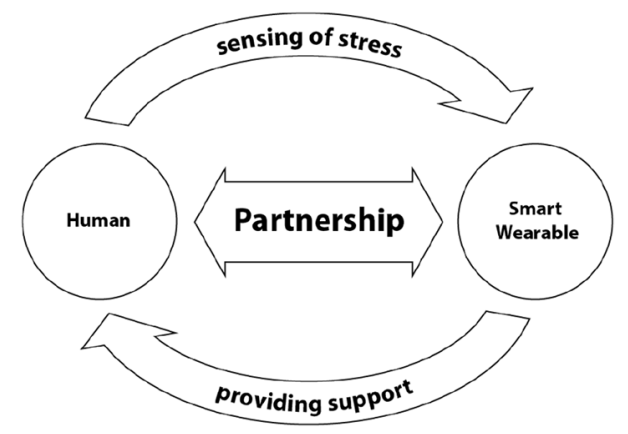

Fig. 1 A preliminary framework of designing smart wearables as partners 
and how they help reduce people's stress. Finally, we suggest designers pay attention to the partner-like characters manifested by smart wearables in interaction. These relational qualities help users gain emotional attachment with wearable products that go beyond their functional purposes. What is still missing in this framework is how this is supported by empirical work and how it can inform the design process in practice. For this purpose, we conducted an empirical study with veterans with chronic PTSD.

\section{Empirical study}

\subsection{Aim of this study}

We set out to discover design opportunities and challenges to design smart wearable as partners. Specifically, we focused on the questions of (1) What could be sensed by smart wearables to achieve an integrated understanding of the individual? (2) How could smart wearables support the individual to deal with stress? and (3) What relational qualities of smart wearables are needed to be perceived as partners? Posttraumatic stress disorder (PTSD) is a stress disorder developed after experiencing a traumatic event (Friedman 2015; Vermetten et al. 2018). A typical symptom of PTSD is that people feel tense on a daily basis and can be easily triggered by stimuli that remind them of their traumatic experiences. Post-war veterans are a group of people who are especially vulnerable and have a high chance of developing PTSD after their service (Yehuda et al. 2014). We chose veterans with chronic PTSD as participants of this study because they are experienced in dealing with daily stress and are potential users who could greatly benefit from the smart wearables we propose.

\subsection{Participants}

Three veterans with PTSD participated in the study. They were recruited through veteran organizations and a mental healthcare institution. Their spouses were also involved as they support the veterans when needed and provided complementary information related to the veterans' stress experiences. Below is a brief overview of the participants and their spouses. Their names have been replaced with code names for anonymization.

Jason, aged 57, was recruited by the military at 16 and sent to an active battle zone aged 20. After his service, he worked for several years until he was diagnosed with PTSD and became unemployed. He received treatment between 2004 and 2010, and has now returned to work at a security company. His wife, Mara, is a psychiatrist nurse. They have three daughters and another two daughters from Jason's previous marriage.
Pete, aged 47, has been undergoing therapy for years, including 9 months' initial treatment, and two years of cognitive behavioral therapy (CBT). He was assessed as being unfit for work. He is now the chairman of a veteran association and occasionally volunteers at a local community sport club. His wife, Mary, aged 46, works for an internet company. They have three sons, one of them from Pete's prior relationship.

Jack, aged 58, was diagnosed with PTSD after his return, and has been disqualified for working for over 20 years. He has undergone a variety of treatments since then, including CBT. Years ago, he experienced a severe scooter accident which causes him constant physical pain and aggravates his mental conditions. He is married to his second wife, Catherine.

\subsection{Procedure}

After confirmation, each couple was invited to an introductory meeting where they were introduced to the content of the study and signed their informed consent. They were given a psychiatrist's contact information in case psychological support was needed. Our study consisted of three parts: (1) Vlogs, (2) follow-up interviews and (3) a co-design workshop. In the first two parts, we learned about the participants' daily stress experiences. In the third part, a setting was provided where they were facilitated to design smart wearables as partners in duo with design students.

\subsubsection{Vlogs}

The veterans were asked to share self-made videos (5-15min vlogs) with the researcher through WhatsApp throughout the course of 1 week. Their spouses were encouraged to assist in making these vlogs. Specific themes were assigned to them each day. On the first 2 days, they were asked to introduce themselves and show "a day in the life". On the third day, they were asked to talk about "the things they carried with them on a daily basis" to inform us about the objects they often use, and how they wear or carry them. On the fourth and fifth days, they shared stressful moments they encountered in daily life and talked about how they handled them. On Day Six, the topic was about support from 'the people you care about'. And on the last day, they reflected on their experiences over the past week.

This method is adapted from self-diaries in user-centered design research (Sanders 2002). We chose this method because it allows the participants to express themselves freely without the pressure caused by the presence of the researcher. Videos uploaded by the participants were reviewed by the researcher and were revisited in the followup interviews. 


\subsubsection{Follow-up interviews}

All of the interviews were held at the participants' homes, and lasted from $30 \mathrm{~min}$ to $2 \mathrm{~h}$. The interviews follow the same structure as that of the vlogs. Some preliminary findings from the vlogs were used as triggers of the conversation.

\subsubsection{Co-creation workshop}

Finally, two veterans, Jason and Pete, and one spouse, Mary (Pete's wife) were invited to a co-creation workshop. The aim of the workshop was to enable the participants to design smart wearables for their own use. Three design students joined them and they formed three teams of two. In the workshop, each team was asked to produce an experience map. We adapted this tool from a user-research toolkit (Path 2013) to provide a structured template to capture the veterans and the spouse' feelings, thoughts and actions throughout different phases of particular stressful situations. Based on this, each team proposed a design concept in forms of a quickly made mock-up. We provided tinkering materials such as scissors, tapes, Velcro and fabrics to assist them in making the mock-ups. The design students helped the veterans and the spouse to clarify and enact their design ideas. Each team presented their work to the others after each of these two exercises.

\subsection{Data management and analysis}

Data were collected from three sources: vlogs, the followup interviews, and presentations of participants' work (experience maps and mock-ups) in the workshop. The data analysis was based on phenomenological research methods (Moustakas 1994) and qualitative content analysis (Hsieh and Shannon 2005). We took three steps to interpret the empirical data from the veterans and their spouses. First, the researcher went through all the data to become familiar with the contents. Specific words or sentences were highlighted as important cues, with preliminary insights noted besides the quotes. The researcher then processed the transcripts more thoroughly and structurally. More insights were generated and grouped under the structure of the outline. Finally, three other external researchers were invited to a discussion to review the insights and to arrive at consensus.

\section{Results}

Results of the study are grouped according to the three points of our design approach: means of sensing, ways of providing support, and ways in which smart wearables are experienced as partners.

\subsection{Means of sensing stress}

\subsubsection{Understanding the person}

All three veterans talked about situations in which they were stressed and agitated but were unaware of the stress at those moments. Catherine, Jack's wife, recalled what she saw when she and Jack were waiting in line at an airport: "He started sweating and I could see he was getting restless". She added that Jack seemed unaware of it. Pete responded to this point by saying that he was always too late becoming aware of his increasing stress. Pete commented on his issue of anger using the metaphor of a ragethermometer: "for anyone it may be 30 or $40 \%$ but I go up to $100 \%$ in no time".

The veterans could show confronting behaviors in stressful situations. All three veterans explained how they struggled with their confronting behaviors caused by agitation and anger. Jason said he sometimes showed fierce reactions when someone suddenly touched him. Pete mentioned that he would use bad language and raise his voice whenever he felt threatened. Jack even got into a fight when someone bumped into him by accident.

The veterans maintained objective perspectives when reflecting on their stress issues. Pete regretted his behaviors when he confronted a lady who cut in line at a bus stop; he admitted that the problem is that he always became aware of this too late. Jason recalled how he overcame his fear of going outside his house step by step. He said he would train himself to be exposed in the situation even though he knew that would wear him out. He also pointed out the significance of "training your physical strength, and not avoiding problems" so that he could return to society. He also shared his comments on the stigma of being a patient and a damaged veteran. He related to people who are like him: "that is basically the worst part... it makes people lose their dignity".

In summary, participants' insensitivity and delayed awareness of their stress show the importance of keeping track of stress in real time. In relation to this issue, physiological sensors show potential to sense immediate arousal of stress at the moment or even in advance (Plarre et al. 2011). The veterans' confronting behaviors in response to intense stress provide some cues of sensing stress through 
their behaviors (body movements) or the use of language. On the other hand, their reflections show the possibility of engaging them to reflect on their own behaviors through which they could grow and develop skills to better cope with stress.

\subsubsection{Understanding the situation}

We recognized specific environmental stimuli that caused the veterans' stress. They were especially triggered by unfamiliar places and people. Jack mentioned that visiting the supermarket really drove him mad and Jason talked about his high alertness whenever he went outside. Other triggers include unexpected objects or sound. For example, Pete shared his fear of thunderstorms and fireworks which gave him: "a terrible fright". Jason expressed his high tension raised by unexpected encounters with people: "if suddenly someone touches me when I do not see it coming...".

We also discovered that veterans' stress was triggered in social situations where they witnessed behaviors that contrasted with their personal values, or where they felt undermined or disrespected by someone. For example, Jack mentioned his immediately increasing tension when he saw a young man cutting the line in a snack shop. Pete commented that he was especially annoyed by his teenage son lying on the couch with eyes on the phone while talking with him, which he referred to as a sign of no respect.

These insights led us to the consideration of context awareness through smart wearables. For example, by coupling sensed environmental data with assessing a person's level of stress might help identify what these triggers are, even before they manifest themselves. Smart wearables could mark particular areas (via GPS trackers) as being potentially stressful and might be used in interventions to help a person prepare for a stressful episode. However, it may be difficult to detect sources of stress in social situations as multiple actors are involved.

To conclude, the combination of individual and contextual information provides a holistic understanding of what triggers people's stress in a particular setting, and opens up a range of possibilities to help them cope with stress.

\subsection{Ways of providing support}

\subsubsection{Raise awareness}

The sensing capabilities of wearable technologies make it possible to remind people of their stress even before the stressful event occurs (Vermetten et al. 2020). The question is whether, at which point, and in which way. Pete expressed his desire that someone could remind or even stop him when he was about to lose control. In the co-design workshop, he designed a smart watch which could send a 'beep' sound and vibration. He commented that these strong and firm signals could pull him back to reality and make him more aware of his behaviors in relation to others. In contrast, Jason preferred quiet and private signals as feedback, as demonstrated by the bracelet described in the introduction. Mary designed a smart table lamp which could sense and moderate the group tension in family conversations. Although a table lamp does not count as a wearable, we included this design as it provides underlying concerns about managing stress in family situations. The table lamp could sense changes of tension in a group conversation by detecting tones and voices, and manifest these changes by changing the color of the light from white to red as tensions develop. According to her, nobody would be pointed at for triggering the signal, so the person could make a change without explicitly mentioning it. With this design, Mary hoped that family members would be more aware of the influence of their behavior on the others.

\subsubsection{Assisting coping behavior}

We identified a number of coping behaviors manifested by the veterans. Some concepts of smart wearables were designed in the workshop to assist their coping behaviors. This was especially exemplified by Jason' design. The different intensities of the bracelet made him realize the level of urgency of the situation, and whether he should withdraw and ask for help from others. Similarly, the smart watch designed by Pete sent a warning signal (sound and vibration), which was interpreted by him as an indication that he should withdraw from the situation before he lost his temper. We note that the indication of these signals and how they invite the users (veterans) to take action largely depends on personal interpretations. This raises the consideration of self-tailored signals of smart wearables, and the training process through which people could associate the signals with particular behaviors that smart wearables intend to elicit.

\subsubsection{Mobilizing human support}

Veterans mentioned the support they received from their social network when dealing with their stress. All three veterans expressed their gratefulness towards their spouses for supporting them through difficult times. Mary, Pete's wife, described her role as a mediator in solving conflicts between Pete and their children, by talking to each other after a fight. Jason expressed his thanks to his wife, Mara, for her understanding and emotional support. This made us consider designing smart wearables to facilitate these relationships. In addition, Jason mentioned the possibility of sharing his stress-related data (collected by the bracelet) with the therapists, saying that: "this (the bracelet) can be given and used by therapists before an appointment. Therapists can log into 
your account and see how many stress moments you have had and see what happened".

From the above, we see how smart wearables could help people deal with their stress by raising awareness, assisting existing coping behaviors, and mobilizing social and therapeutic support. Examples given by the participants show that people interpret the wearable signals differently and associate these with particular coping behaviors. With regards to this point, we see the possibility of integrating artificial intelligence in the design of smart wearables, which can play an important role in tailoring these specific forms of support in respectful and responsible ways. Although some AI techniques such as machine learning algorithms have been used to train the wearable systems to be more accurate in recognizing stress (Grünerbl et al. 2014; Garcia-Ceja et al. 2015), a review of the field of digital health interventions shows that more work should be done with respect to interventions and their effects in real life (Triantafyllidis and Tsanas 2019). Furthermore, smart wearables also open up opportunities for sharing stress-related information with family members and therapists. This could bring opportunities to foster social support and eHealth service for mental health.

\subsection{Experienced partnership qualities}

In this section, we present the insights gained about the important relational qualities of smart wearables as appreciated by the participants.

\subsubsection{Trustworthiness}

Smart wearables have to be trusted by their user. When talking about the 'personalities' that the smart watch should possess, Pete referred to his wife who could help him make the right decision even if it was hard for him to accept at that moment. He therefore designed a strong and firm smart watch. Jason describes the 'quality' of his bracelet by referring to it as his "best friend" which gives him room to challenge himself. This is reflected by the bracelet giving signals on multiple levels so that he could: "search for your [his] own limits". Mary referred to the table lamp as a family member who could read the subtle change of mood in the air and express it empathically.

\subsubsection{Respectfulness}

The smart wearables have to be respectful and show concerns for personal values. On this point, Pete admitted that the watch might be difficult to use since withdrawal from conflicts with others might make him feel weak and give him a sense of failure. Jason said that his military experience had trained him to stick with principles and authority. Any suggestions that compromised these values could be difficult for him to follow. Mary's design of the table lamp shows the respect for personal privacy and not revealing personal feelings in group conversations. Additionally, the smart wearables should allow users autonomy when making their own decisions. This is exemplified by the bracelet which intended to raise Jason's awareness (through contraction) but was put asleep by him (by tapping on it twice). According to Mary, the signals sent by the table lamp could be easily ignored, and would stop when not attended after a short time.

\subsubsection{Discreetness}

Smart wearables should be discreet regarding the physical settings and social situations. This was especially demonstrated by the design of the table lamp, which, according to Mary, should look like part of the interior so that visitors would not recognize it. The changing colors of light indicate the group's tension, but not that of individuals. These meanings would only be shared within the family. Jason designed the bracelet to silently communicate with him to avoid attention from others. He also chose rubbing and tapping as ways of communicating with the bracelet which are natural gestures that would not draw too much attention from others.

To summarize, the style of interaction with smart wearables reflects their relational qualities of being trustworthy, respectful and discreet. These are constructive elements for building up partnerships with the wearables. The insights show that these qualities can be designed with consideration of people's appreciation of human characters, personal values, life habits, and social environments.

\section{Discussion}

We reflect on how the results of the study can enrich our approach in terms of sensing, intervention (providing support) and relationship with smart wearables. We also discuss the potential implications on stress management caused by this approach and the relevant social and ethical concerns. We conclude the discussion by reflecting on limitations and look further at future work.

\subsection{Designing smart wearables as partners}

\subsubsection{Aggregation of multiple sources of data}

As the results show, multiple sources of data can be used to sense a person's daily stress, including individual (physiological signals, physical activities and self-reflection) and contextual (environmental and social) information. For individual sensing, some of the signals are readily accessible through wearable sensors, such as physiological signals and physical activities. Others require the individual's 
input of their subjective feelings and personal values. Thus, particular attention should be paid to designing wearables that invite or intrigue wearers to reflect on their current or historical stressful events. Specifically, the interaction for reporting current stress should fit with the situation and not disturb any current activities. As for reflection on previous stress experiences, the design should provide meaningful ways to link the users back to their earlier experiences. The overall efforts should not bring about negative effects or overburden the users. On the other hand, some situational cues (such as time, locations, and personal schedules) can be used to indicate particular environments and social situations that are potentially stressful for the user. However, there are challenges to identifying those triggers that are particularly stressful for individuals. It is even more complicated when this involves social rules and other people in the situation. An integrated perspective and synthesis techniques are required to combine these situational aspects with the individual's needs, preferences, and preferred coping behaviors. The emerging trend of integrating machine learning in stress detection is a promising way of addressing this issue (Garcia-Ceja et al. 2018).

\subsubsection{Self-tailored, therapeutic and social support}

The veterans participating in this study presented different types of support they preferred in different situations, including raising awareness, associating with their coping strategies, and mobilizing social support. Several types of signals were mentioned by the participants as ways to raise their stress awareness. Jason used contractions of different intensity as the stress reminder. Pete chose the sound of an alarm and vibration as warning signals. Mary used the colors of light as a group tension indicator. Factors that affected their selection of these signals include their personal preferences, correlation with stress levels, and appropriateness in social situations.

We also see opportunities to design smart wearables that facilitate people's coping behaviors from therapeutic and social perspectives. Such action indications largely depend on personal interpretation, and sometimes the function of raising awareness and action guidance can be mixed together. For example, the smart watch's warning signal was also interpreted by Pete as a withdrawal signal. Moreover, it is a challenge to decide which coping strategies are appropriate and how they would work to help the person. The discussion on appropriate coping behaviors is ongoing in the field of psychology and depends on their short-term effects on stress and long-term perspectives towards the individual's development (Thwaites and Freeston 2005). For example, avoiding stressful social situations can keep the person away from the potential risks in the short term, but could result in him or her becoming isolated from society in the long term. Professional guidance is needed that not only help the person to decide on suitable coping strategies in the situation, but also benefit him or her for long-term development. Jason specifically suggested sharing the data collected by the bracelet with family members and therapists, which could then be further integrated as part of the therapeutic treatment.

\subsubsection{Smart wearables experienced as partners}

As indicated by the approach, we suggest designing smart wearables that form a partnership with the wearer. Results of our study provide insights into the experiential qualities of such partners. The smart wearables should be trustworthy, respectful and discreet. The quality of trustworthiness expresses the veterans' wishes that wearable could help them to do the right thing at the right time, encourage them to challenge themselves, and to communicate in an empathic way. Respectfulness emphasizes that smart wearables should be aware of the users' limits (privacy and personal values) and permit the autonomy to make their own decisions. With discreetness, we emphasize the sensitivity of the design to social situations. These qualities can form general guidelines for driving design considerations on the other aspects of the approach. More questions follow, for example, how the appearance, behavior and interactivity of the wearable can trigger particular perceptions, and to what extent we could relate smart wearables to the counterparts of humans and animals. In design theories, some notions, such as anthropomorphism, zoomorphism and animism, can be valuable aids when designing these signs of intelligence and agency in their interaction with humans (Marenko 2014; Rozendaal et al. 2019; Jung et al. 2017).

\subsection{Design implications}

Our design approach raises some concerns on the implications brought by technological interventions in mental healthcare. In the field of HCI, attention has been paid to the role of interactive artifacts to empower people in behavioral change (Johnstone 2007; Höök et al. 2008). This reconciles with the shift of focus in mental healthcare from diagnosis and treatment based on symptoms, to preventive interventions based on risk assessment (Tartarisco et al. 2012). Our study provides a specific context of designing for daily stress, in which particular perspectives and design strategies need to be developed. Specifically, our approach calls for a design direction that empowers individuals with sensitivity and knowledge to identify and deal with their mental issues on a daily basis. It also provides an overall perspective for viewing the current development of eHealth interventions for mental health in forms of mobile or wearable applications (Morland et al. 2017; Luxton et al. 2011). 
We also recognize some ethical concerns. This is reflected in personal differences in interpreting stress notifications and interventions and the different levels of authority and autonomy requested by the participants when it comes to making decisions. For example, Pete preferred strong and loud signals that could bring him back to reality, while Jason chose a private and flexible manner to communicate with the bracelet. This raises the question of to which extent we should allow for (wearable) technologies to take the initiatives on behalf of the users. Concerns might arise that too great a reliance on these technologies could undermine the person's resilience and ability to deal with stress. Therefore, we should make sure that we design smart wearables that are responsible and value sensitive to help people as they want and within their limits (Van den Hoven 2013; Friedman and Hendry 2019).

\subsection{Limitations and future work}

The phenomenological research conducted in this study is based on a small number of participants. In phenomenology and qualitative research, small sample sizes are common when investigating individual's first-hand experiences. In addition, we aimed to develop design knowledge about wearable technologies for daily stress. Results of this study provide initial anecdotal materials to help us to identify specific directions to address such issues. In the future, larger groups of participants are required to investigate the effectiveness of designs guided by our approach.

We involved veterans with PTSD as individuals who are experienced in dealing with stress. Our purpose was to outline a design approach that opens up new opportunities to design wearable technologies, rather than to provide generalized knowledge on people dealing with stress in general, nor people with PTSD. Veterans with PTSD provide rich individual experiences that help us better understand that direction. However, we should acknowledge that some of the identified coping strategies (for instance, helping a person deal with agitation and anger) might be specific to veterans with chronic PTSD. More research is needed to generalize our findings to other user groups and other types of stressrelated issues.

Discussions on the technologies are based on literature research and are on a conceptual level. The empirical materials provided by the participants are based on their recollections of their life experiences and anticipation of the future facilitated by the researcher. The mock-ups were used as prompts for conversations; these may limit the depth of technological details. In future studies, we need to develop multiple prototypes from low fidelity to functional prototypes which can be tested in experimental or real-life settings. In this way, we can test specific assumptions about their impacts and effects following a research-through-design approach (Stappers and Giaccardi 2017), and build up practice-informed design knowledge in forms of intermediate knowledge (Höök and Löwgren 2012; Löwgren 2013).

We would like to conclude this discussion with some remarks about involving participants with a stress-related mental disorder in participatory research. The study was carefully planned and conducted considering the participants' special condition to help give them a voice. For example, in the co-design workshop, three students were involved in the workshop to assist the participants in the creation process. However, we noted that sharing daily life experience by means of vlogs might be technically challenging for some participants. Jack, who dropped out of the study before the workshop, stated that it was difficult for him to think about what to film if there were no strict rules. Thus, future work should also consider participants' expertise and particular life situations, and how they are comfortable with the research tools to be used.

\section{Conclusion}

In this paper we proposed an approach for designing smart wearables as partners to help people cope with daily stress. This approach considers how smart wearables can be designed as partners that consider both the person and the situation so as to provide appropriate support. We describe how this approach is inspired by the technological capabilities of smart wearables, therapeutic partnerships with humans and animals, and the trend of designing everyday computers as partners in HCI. Following this approach, we conducted a study with veterans with PTSD where we identified design opportunities and challenges to design wearables as partners that would help them deal with stress. From the discussion on the results, we learnt the important role to be played by smart wearables when empowering people to manage their daily stress, and that further attention should be paid to inherent ethical concerns. Finally, we reflected on limitations of this study and indicated directions for future work.

Acknowledgements This study has been approved by Human Research Ethics Committee TU Delft on April 21, 2017. This project is funded by the China Scholarship Council (201606790011). Special thanks go to Jet Gispen who helped in communication and interviews with the participants, and Chiwei Luu and Matthijs Vollebregt who assisted the participants during the co-creation workshop.

Open Access This article is licensed under a Creative Commons Attribution 4.0 International License, which permits use, sharing, adaptation, distribution and reproduction in any medium or format, as long as you give appropriate credit to the original author(s) and the source, provide a link to the Creative Commons licence, and indicate if changes were made. The images or other third party material in this article are included in the article's Creative Commons licence, unless indicated 
otherwise in a credit line to the material. If material is not included in the article's Creative Commons licence and your intended use is not permitted by statutory regulation or exceeds the permitted use, you will need to obtain permission directly from the copyright holder. To view a copy of this licence, visit http://creativecommons.org/licenses/by/4.0/.

\section{References}

Adams P, Rabbi M, Rahman T, Matthews M, Voida A, Gay G, et al (2014) Towards personal stress informatics: comparing minimally invasive techniques for measuring daily stress in the wild. In: Proceedings of the 8th International Conference on Pervasive Computing Technologies for Healthcare, pp 72-79.

Anderson NB, Johnson S, Belar C, Breckler S, Nordal K, Ballard D (2012) Stress in America: Our health at risk. American Psychological Association.

Bakker J, Holenderski L, Kocielnik R, Pechenizkiy M, Sidorova N(2012) Stess@ work: From measuring stress to its understanding, prediction and handling with personalized coaching. In: Proceedings of the 2nd ACM SIGHIT International health informatics symposium, pp 673-678. ACM.

Brantley PJ, Jones GN (1993) Daily stress and stress-related disorders. Ann Behav Med 15(1):17-25

Cila N, Smit I, Giaccardi E, Kröse B (2017) Products as agents: Metaphors for designing the products of the IoT age. In: Proceedings of the 2017 CHI Conference on Human Factors in Computing Systems, pp 448-459. ACM.

Cohen S, Wills TA (1985) Stress, social support, and the buffering hypothesis. Psychol Bull 98:310-357

Cruz L, Rubin J, Abreu R, Ahern S, Eldardiry H, Bobrow DG (2015) A wearable and mobile intervention delivery system for individuals with panic disorder. In: Proceedings of the 14th International Conference on Mobile and Ubiquitous Multimedia, pp 175-182. ACM.

Donker T, Petrie K, Proudfoot J, Clarke J, Birch MR, Christensen $\mathrm{H}$ (2013) Smartphones for smarter delivery of mental health programs: a systematic review. J Med Internet Res 15(11):e247

Dotson MJ, Hyatt EM (2008) Understanding dog-human companionship. J Business Res 61(5):457-466

Farooq U, Grudin J (2016) Human-computer integration. Interactions 23(6):26-32

Ferdous R, Osmani V, Mayora O (2015) Smartphone app usage as a predictor of perceived stress levels at workplace. In: 2015 9th International Conference on Pervasive Computing Technologies for Healthcare (PervasiveHealth), pp 225-228. IEEE.

Ferreira P, Sanches P, Höök K, Jaensson T (2008) License to chill! How to empower users to cope with stress. In: Proceedings of the 5th Nordic conference on Human-computer interaction: building bridges, pp 123-132.

Friedman MJ (2015) Posttraumatic and acute stress disorders. Springer, Berlin

Friedman B, Hendry DG (2019) Value sensitive design: shaping technology with moral imagination. Mit Press, Cambridge

Garcia-Ceja E, Osmani V, Mayora O (2015) Automatic stress detection in working environments from smartphones' accelerometer data: a first step. IEEE J Biomed Health Info 20(4):1053-1060

Garcia-Ceja E, Riegler M, Nordgreen T, Jakobsen P, Oedegaard KJ, Tørresen J (2018) Mental health monitoring with multimodal sensing and machine learning: a survey. Pervasive Mob Comput 51:1-26

Grünerbl A, Muaremi A, Osmani V, Bahle G, Oehler S, Tröster G et al (2014) Smartphone-based recognition of states and state changes in bipolar disorder patients. IEEE J Biomed Health Info 19(1):140-148

Holbrook MB, Stephens DL, Day E, Holbrook SM, Strazar G (2001) A collective stereographic photo essay on key aspects of animal companionship: the truth about dogs and cats. Acad Mark Sci Rev 1(1):1-16

Höök K, Löwgren J (2012) Strong concepts: Intermediate-level knowledge in interaction design research. ACM Trans ComputHum Interact (TOCHI) 19(3):1-18

Höök K, Ståhl A, Sundström P, Laaksolaahti J (2008) Interactional empowerment. In: Proceedings of the SIGCHI Conference on Human Factors in Computing Systems, pp 647-656.

Hsieh HF, Shannon SE (2005) Three approaches to qualitative content analysis. Qual Health Res 15(9):1277-1288

Jacucci G, Spagnolli A, Freeman J, Gamberini L (2014) Symbiotic interaction: a critical definition and comparison to other humancomputer paradigms. In: International Workshop on Symbiotic Interaction. Springer, Cham, pp 3-20

Janlert LE, Stolterman E (1997) The character of things. Des Stud $18(3): 297-314$

Johnstone J (2007) Technology as empowerment: a capability approach to computer ethics. Ethics Inf Technol 9(1):73-87

Jung H, Wiltse H, Wiberg M, Stolterman E (2017) Metaphors, materialities, and affordances: hybrid morphologies in the design of interactive artifacts. Des Stud 53:24-46

Kelley C, Lee B, Wilcox L (2017) Self-tracking for mental wellness: understanding expert perspectives and student experiences. In: Proceedings of the 2017 CHI Conference on Human Factors in Computing Systems, pp 629-641.

Lazarus RS, Folkman S (1984) Stress, appraisal and coping. Springer Publishing Company, New York

Lovallo WR (2015) Stress and health: Biological and psychological interactions. Sage publications, Thousand Oaks

Löwgren J (2013) Annotated portfolios and other forms of intermediate-level knowledge. Interactions 20(1):30-34

Luxton DD, McCann RA, Bush NE, Mishkind MC, Reger GM (2011) mHealth for mental health: integrating smartphone technology in behavioral healthcare. Prof Psychol 42(6):505

MacLean D, Roseway A, Czerwinski M (2013) MoodWings: a wearable biofeedback device for real-time stress intervention. In: Proceedings of the 6th international conference on PErvasive Technologies Related to Assistive Environments, p 66. ACM.

Marenko B (2014) Neo-animism and design. Design and Culture 17(2):218-237

Mark G, Wang Y, Niiya M (2014) Stress and multitasking in everyday college life: an empirical study of online activity. Proc CHI

Miller L (1998) Our own medicine: traumatized psychotherapists and the stresses of doing therapy. Psychotherapy 35(2):137

Morland LA, Greene CJ, Rosen CS, Kuhn E, Hoffman J, Sloan DM (2017) Telehealth and eHealth interventions for posttraumatic stress disorder. Curr Opin Psychol 14:102-108

Moustakas C (1994) Phenomenological research methods. Sage, Thousand Oaks

Nicolson NA (1992) Stress, coping and cortisol dynamics in daily life. The experience of psychopathology: investigating mental disorders in their natural settings, pp 219-232

Path A (2013) Adaptive path's guide to experience mapping. Retrieved 20 Jan 2018.

Patterson GT (2003) Examining the effects of coping and social support on work and life stress among police officers. J Crim Justice 31(3):215-226

Plarre K, Raij A, Hossain SM, Ali AA, Nakajima M, Al'Absi M, et al (2011) Continuous inference of psychological stress from sensory measurements collected in the natural environment. In: Information Processing in Sensor Networks (IPSN), 2011 10th International Conference on, pp 97-108. IEEE. 
Reece AG, Danforth CM (2017) Instagram photos reveal predictive markers of depression. EPJ Data Sci 6(1):1-12

Rozendaal MC (2016) Objects with intent: a new paradigm for interaction design. Interactions 23(3):62-65

Rozendaal MC, Boon B, Kaptelinin V (2019) Objects with intent: designing everyday things as collaborative partners. ACM Trans Comput-Hum Interact (TOCHI) 26(4):1-33

Sanches P, Höök K, Vaara E, Weymann C, Bylund M, Ferreira P, et al (2010) Mind the body!: designing a mobile stress management application encouraging personal reflection. In: Proceedings of the 8th ACM conference on designing interactive systems, pp 47-56. ACM.

Sanders EBN (2002) From user-centered to participatory design approaches. In design and the social sciences. CRC Press, Boca Raton, pp 18-25

Schwartz HA, Eichstaedt J, Kern ML, Park G, Sap M, Stillwell D, et al (2014) Towards assessing changes in degree of depression through facebook. In: Proceedings of the Workshop on Computational Linguistics and Clinical Psychology: From Linguistic Signal to Clinical Reality, pp 118-125.

Sharmin M, Raij A, Epstien D, Nahum-Shani I, Beck JG, Vhaduri S, et al (2015) Visualization of time-series sensor data to inform the design of just-in-time adaptive stress interventions. In: Proceedings of the 2015 ACM International Joint Conference on Pervasive and Ubiquitous Computing, pp 505-516.

Smedberg $\AA$, Sandmark H (2012) Design of a mobile phone app prototype for reflections on perceived stress. In: The Fourth International Conference on eHealth, Telemedicine and Social Medicine. eTELEMED

Stappers P, Giaccardi E (2017) Research through design. The encyclopedia of human-computer interaction 1-94.

Steptoe A, Fieldman G, Evans O, Perry L (1996) Cardiovascular risk and responsivity to mental stress: the influence of age, gender and risk factors. J Cardiovasc Risk 3(1):83-93

Tartarisco G, Baldus G, Corda D, Raso R, Arnao A, Ferro M et al (2012) Personal Health System architecture for stress monitoring and support to clinical decisions. Comput Commun 35(11):1296-1305

Thwaites R, Freeston MH (2005) Safety-seeking behaviours: fact or function? How can we clinically differentiate between safety behaviours and adaptive coping strategies across anxiety disorders? Behav Cogn Psychother 33(2):177-188

Triantafyllidis AK, Tsanas A (2019) Applications of machine learning in real-life digital health interventions: Review of the literature. J Med Internet Res 21(4):e12286

Uğur S, Mangiarotti R, Bordegoni M, Carulli M, Wensveen SAG, Duncker IL (2011) An experimental research project: wearable technology for embodiment of emotions. In: Proceedings of the 2011 Conference on Designing Pleasurable Products and Interfaces, $\mathrm{p}$ 32. ACM.

Van den Hoven J (2013) Value sensitive design and responsible innovation. In: Owen R, Bessant J, Heintz M (eds) Responsible innovation. Wiley, Chichester, pp 75-84

Vermetten E, Baker DG, Risbrough VB (2018) Behavioral neurobiology of PTSD. Springer International Publishing, Berlin

Vermetten E, Tielman ML, van Dort E, Binsch O, Li X, Rozendaal MC et al (2020) Using VR-based interventions, wearable technology, and text mining to improve military and Veteran mental health. J Mil Veteran Family Health 6(S1):26-35

Vincent C, Belleville G, Gagnon DH, Dumont F, Auger E, Lavoie V et al (2017) Effectiveness of service dogs for veterans with PTSD: preliminary outcomes. In: AAATE Conf., pp 130-136

Wang R, Chen F, Chen Z, Li T, Harari G, Tignor S, et al (2014) StudentLife: assessing mental health, academic performance and behavioral trends of college students using smartphones. In: Proceedings of the 2014 ACM international joint conference on pervasive and ubiquitous computing, pp 3-14. ACM

Yehuda R, Vermetten E, McFarlane AC, Lehrner A (2014) PTSD in the military: special considerations for understanding prevalence, pathophysiology and treatment following deployment. Eur J Psychotraumatol 5(1):25322

Yount R, Ritchie EC, Laurent MS, Chumley P, Olmert MD (2013) The role of service dog training in the treatment of combat-related PTSD. Psychiatr Ann 43(6):292-295

Publisher's Note Springer Nature remains neutral with regard to jurisdictional claims in published maps and institutional affiliations. 